\title{
AN ANALYSIS OF THE POSTAL MARKET CONCERNING 24/7 COURIER SERVICE AVAILABILITY
}

\author{
Dragan Lazarević1, Momčilo Dobrodolac 1,, ${ }^{*}$ Predrag Ralević
}

\begin{abstract}
In this paper, we analyzed the readiness and needs of the postal market for the concept of express delivery service with improved time availability, which together with the existing services includes 24/7 customer service. On the territory of the city of Belgrade, a survey was conducted on the attitudes and needs for the existing services of express shipments, as well as for the proposed new service, in order to obtain appropriate indicators. The research involved creating an appropriate questionnaire and collecting the opinions of respondents, which consisted of individuals and legal entities. The collected data were statistically analyzed, and the most significant results were presented in the paper.
\end{abstract}

Keywords express delivery service; shipments; postal company; new service; time availability

\section{INTRODUCTION}

Contemporary business environments and changing habits and requirements of private users have made the systems of service activities, and thus including the delivery of shipments, to face numerous challenges on a daily basis, both at the organizational and operational levels. This is also influenced by changes in society, both locally and globally. In the past, there were different crises, such as various conflicts and economic crises, while today there is the impact of the coronavirus pandemic (COVID-19). In such circumstances, in addition to the limitations that already exist in the system, new and more complex ones appear, which must be taken into consideration. For that reason, the management of a company that deals with the delivery of shipments must consider all the threats and opportunities, in order to organize the business process in a way that customers are satisfied, while achieving a satisfactory income.

These changes in the environment affect the change in people's habits and therefore change their demands for delivery services. Among other things and for that reason, it is necessary to analyze the market, and based on the results of the analysis, to determine appropriate activities and business models. Business process performance analysis is certainly one of the important steps in offering a service of the highest level of quality. A tool that is often used in the literature is the application of SWOT analysis, where all strengths, weaknesses, opportunities, and threats are analyzed through a systematic approach. With a combined application with the appropriate method of multi-criteria analysis, influencing factors or alternatives can be ranked and singled out by importance (Dobrodolac et al., 2016). The idea for creating such a model resulted from a similar concept combining AHP and SWOT (A'WOT method), which can be found in the literature (Görener, 2012). The experts express their opinions on the basis of Saaty's

\footnotetext{
${ }^{1}$ Faculty of Transport and Traffic Engineering, University of Belgrade, Vojvode Stepe 305, 11000 Belgrade, Serbia

2 Technical College of Applied Sciences, Uroševac (Leposavić), 24. Novembar bb, 38218 Leposavić, Serbia

*corresponding author: Momčilo Dobrodolac, e-mail: m.dobrodolac@sf.bg.ac.rs
} 
comparison scale (Saaty, 1977). Several such analyses were conducted on the example of postal companies from Serbia. In one of the latest ones, a new model for analysis was developed - A'BA model, which represents a combined application of Analytic Hierarchy Process - AHP method as a multi-criteria decision-making tool and theory of business areas (Lazarević et al., 2020a). In the analysis, 31 influencing factors on business performance have been devised, as well as 6 business areas in which the factors are distributed. Although the improvement of the technology process in the courier service is very important (Dobrodolac et al., 2012), the methodology applied by Lazarević et al., 2020a showed that the market situation analysis, as one of the business areas, is of crucial importance as well.

The paper presents an analysis that primarily refers to the postal market concerning $24 / 7$ courier service availability. Today's time frames, from the aspect of a business, imply that workers spend a significant amount of time at work. When the commuting time is included, the situation is that people cannot complete everyday life obligations and fulfill certain needs, because their free time does not coincide with the working hours of institutions and companies of interest. This is often the case among users from one side and courier companies and systems on the other. When it comes to legal entities as service users, the epilogue is similar, while the reasons and consequences are different. Namely, when a legal entity uses services of transfer of express shipments within its own working hours, it can cause negative consequences on the efficiency of its current business activities (Dias et al., 2019).

Companies strive to retain existing and attract new customers by improving the quality of services. One of the successful approaches is certainly to adjust services in order to meet the needs of the people (Edvardsson, 1998). This approach implies that the needs of users are met gradually, starting from identifying the needs and then improving the quality of service (Bergman and Klefsjö, 2010). Numerous authors have dealt with the improvement of quality and the development of business strategies in the postal sector (Dobrodolac et a., 2014). Various approaches and models have been developed to improve and determine the level of quality of postal and other public services (Spajić and Šapina, 2007; Brysland and Curry, 2001). Many approaches to quality improvement in this area are based on the application of multi-criteria analysis. Some of the examples are the improvement of quality in the Korean shipment system, as well as the formation of a strategy for improving the business of the Chinese shipment service (Wang et al., 2014).

When it comes to the availability of a certain service, it mainly refers to its territorial, financial, and time availability. Improving availability is a step forward to improving the quality and performance of the service (Kashiki et al., 2010). Further related to the above mentioned, it can be concluded that the improvement of time availability would solve the mentioned emerging problems related to the use of the delivery service by individuals and legal entities. Namely, the periods of time in which the express delivery service is not performed may be interesting to the companies that provide the service, but above all, to potential users. Therefore, a new service with improved time availability is proposed here. On the territory of the city of Belgrade, a survey was conducted on the attitudes and potential demands for the existing delivery services (EDS), as well as for the proposed new delivery service (NDS). The paper highlights and presents the most significant results.

\section{METHODOLOGY}

The research included the creation of a questionnaire, as well as the collection and analysis of respondents' answers. In the first part of the questionnaire, there are questions about the demographic data of the respondents, while the second part includes questions that define the habits and attitudes of the respondents about the EDS. The last part of the questionnaire includes questions related to the examination of attitudes about the proposed NDS.

The target group of respondents related to individuals and legal entities from the Belgrade city area. The questionnaire was published on the Google platform. Answers were gathered in two ways: individual 
respondent answering and interviewing of respondents by researchers. In the second case, the obtained answers were inserted into the web-based questionnaire. Gathered data were statistically analyzed in the software IBM SPSS Statistics v. 21 (Statistical Package for the Social Science). The normality of distribution was tested by using the Kolmogorov-Smirnov test, whereby it was noticed that distributions of continuous variables significantly statistically deviated from the normal distribution. In line with this fact, in further analysis, nonparametric methods were used. For assessment of the correlation of variables, the Chi-square independence test was used. For testing of differences between two independent groups with respect to a continuous variable, the Mann-Whitney U test was used, while in the case of three or more independent groups, the Kruskal-Wallis test was used (Pallant, 2011). Binary logistic regression was used in order to evaluate the effect of certain independent variables on the possibility for the respondent to be interested in the analyzed service (Dobrodolac and Lazarević, 2019; Lazarević et al., 2020b).

As previously stated, a significant number of individuals and legal entities are not able to use the express delivery services or by using them it negatively affects their other current activities. The most common reason is overlapping the working hours of delivery companies and persons interested in using the service. Periods of time, which are not covered by express delivery services, can be interesting for both providers and potential users of the service.

The new service proposed in the paper has its greatest contribution in the segment of improving time availability. The concept is based on the maximum time coverage of the service during the week (together with existing services), which means that the service on weekdays is performed in the period from $7 \mathrm{pm}$ to $8 \mathrm{am}$, or on weekends from $3 \mathrm{pm}$ on Saturdays to $8 \mathrm{am}$ on Mondays. The process of performing the service would be like the existing services, which means the delivery of the shipment within 3 hours from the moment of receipt, or until $8 \mathrm{am}$. In addition to the basic concept, the possibility would be offered to receive the shipment within the new service, and delivery the next day (or later the same day, if the reception is made at midnight), through existing services. Also, the reception could be performed through the channels of the existing services, and the delivery through the proposed, new service (Dobrodolac and Lazarević, 2019; Lazarević et al., 2020b).

Over time, depending on the need and justification, different modifications of the service could be introduced. In addition to the financial income it would bring to a company, NDS would provide additional positive effects, both for a company and society. Namely, the company that would introduce this service would be the market leader, which would significantly contribute to the brand. The transfer of express shipments in domestic traffic is performed by road. By switching a certain number of requests to NDS, the number of rides during peak network hours would be reduced, thus contributing to the reduction of congestion and driving time. Besides, driving on the city streets in night traffic conditions is possible with significantly lower fuel consumption compared to daytime conditions, which is important for increasing the energy efficiency of the entire system, reducing costs and emissions. In this way, the possibility of social contact between couriers and other people is reduced, which makes a positive impact concerning the preventive measures caused by the coronavirus pandemic (COVID-19). In addition to the above, the service time is reduced, as well as the depreciation of vehicles, while the number of addresses served by a courier increases in a certain period of time (Dobrodolac and Lazarević, 2019; Lazarević et al., 2020b).

\section{SELECTED RESULTS OF THE RESEARCH}

The survey included the answers of a total of 181 respondents, of which 132 respondents were natural persons of different demographic characteristics (72.9\%), while there were 49 legal entities (27.1\%). Part of the group of respondents, related to legal entities, consisted mainly of participants in the relevant ecommerce chains. $81.6 \%$ of these respondents and $78.8 \%$ of natural persons stated that they use one of the existing services EDS - "Today for Now", "Today for Today" and "Today for Tomorrow". The results show that the most frequently used service for the transfer of express shipments - "Today for Tomorrow" and this applies to both groups of respondents (individuals - 87.5\%, legal entities - 92.5\%), while the 
services "Today for Now " and "Today for Today "represented to a lesser extent (natural persons - 12.5\%, legal entities - 7.5\%) (see Fig. 1) (Dobrodolac and Lazarević, 2019; Lazarević et al., 2020b).

Legal entities (92.5\%) use the service of express shipments as senders at least once a week, while natural persons as senders have a significantly smaller share. 78.8\% of individuals send express shipments at least once a year, while almost $4 \%$ do not use the service at all as senders (see Fig. 2).

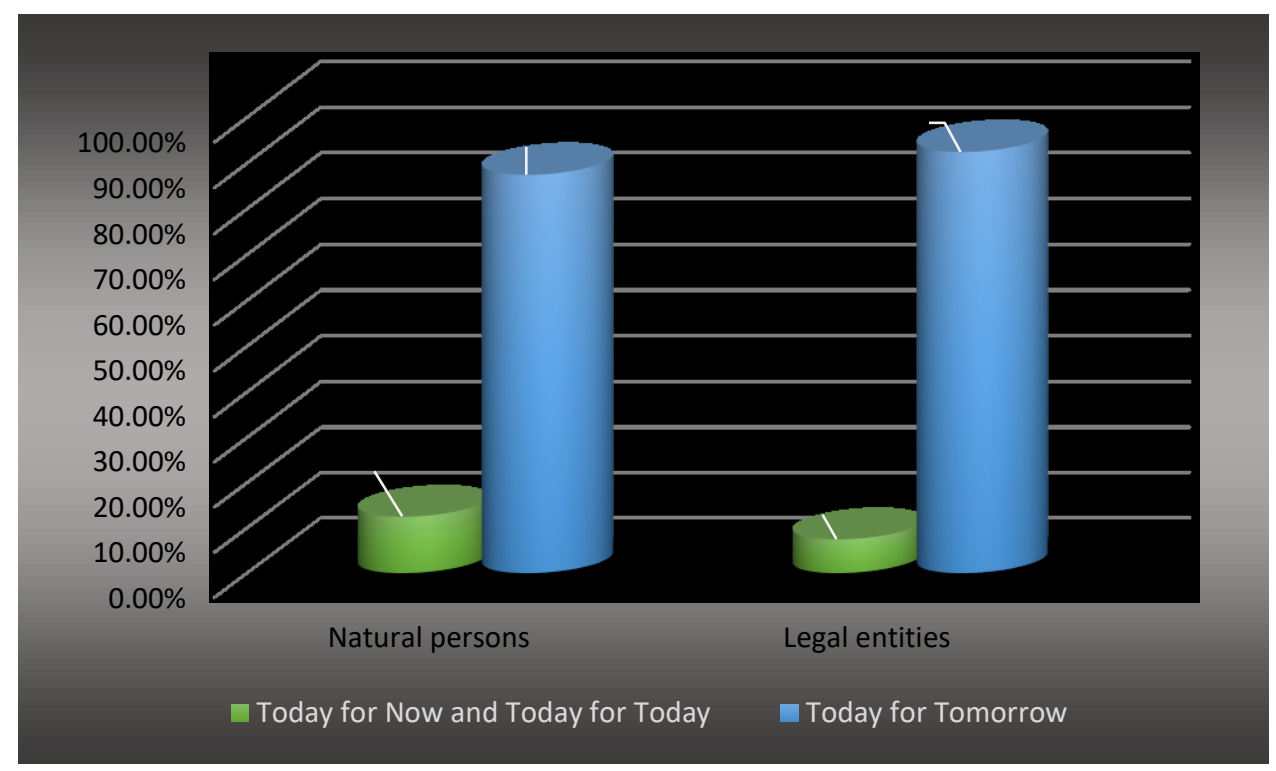

Fig. 1 Representation of type of EDS services for natural and legal persons

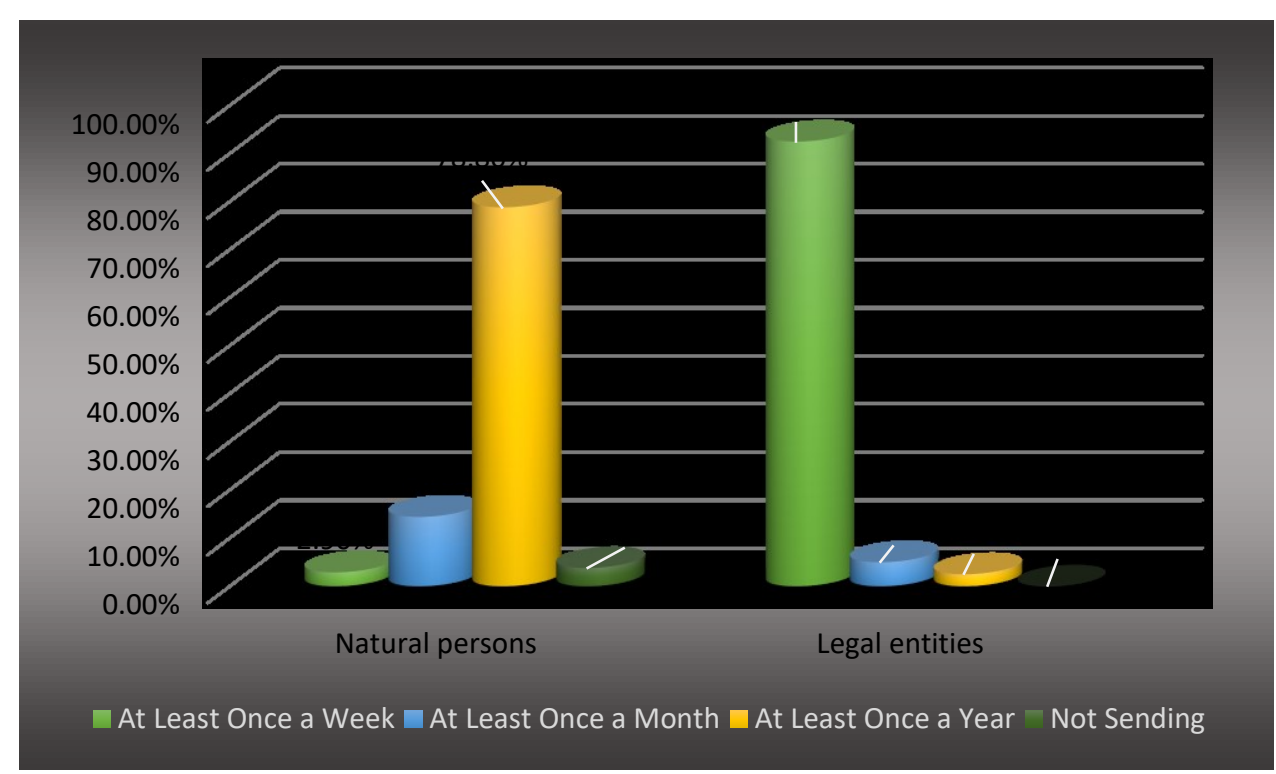

Fig. 2 Frequency of sending express postal items by natural persons and legal entities

In the case of the frequency of receiving express shipments by users, the largest part (57.5\%) of legal entities use the service on a weekly basis, noting that a significant number (35\%) of those who use the service on a monthly basis and $2.5 \%$ of legal entities does not use the service as a recipient. When it comes to individuals, almost $78 \%$ use the service as a recipient at least once a year, while $2 \%$ of individuals do not receive any shipment during the year (see Fig. 3) (Dobrodolac and Lazarević, 2019; Lazarević et al., 2020b). 


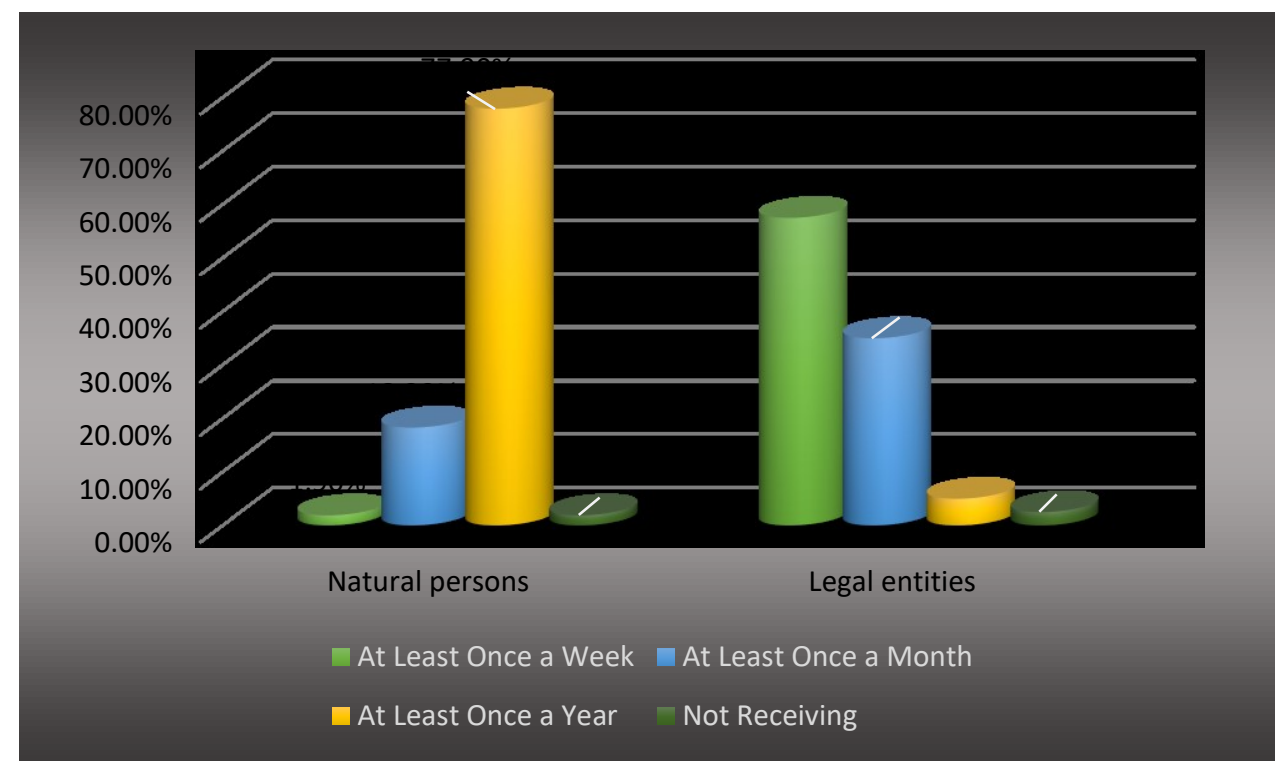

Fig. 3 Frequency of receiving express postal items by natural persons and legal entities

Legal entities sent on average about 855 and received about 123 shipments, while the same indicators for natural persons are about 3 and 5 shipments, respectively. In accordance with the obtained results, it can be concluded that legal entities send more shipments than they receive, while for natural persons. The situation is reversed. This can be explain by the fact that legal entities mainly send goods to customers, who are mostly natural persons.

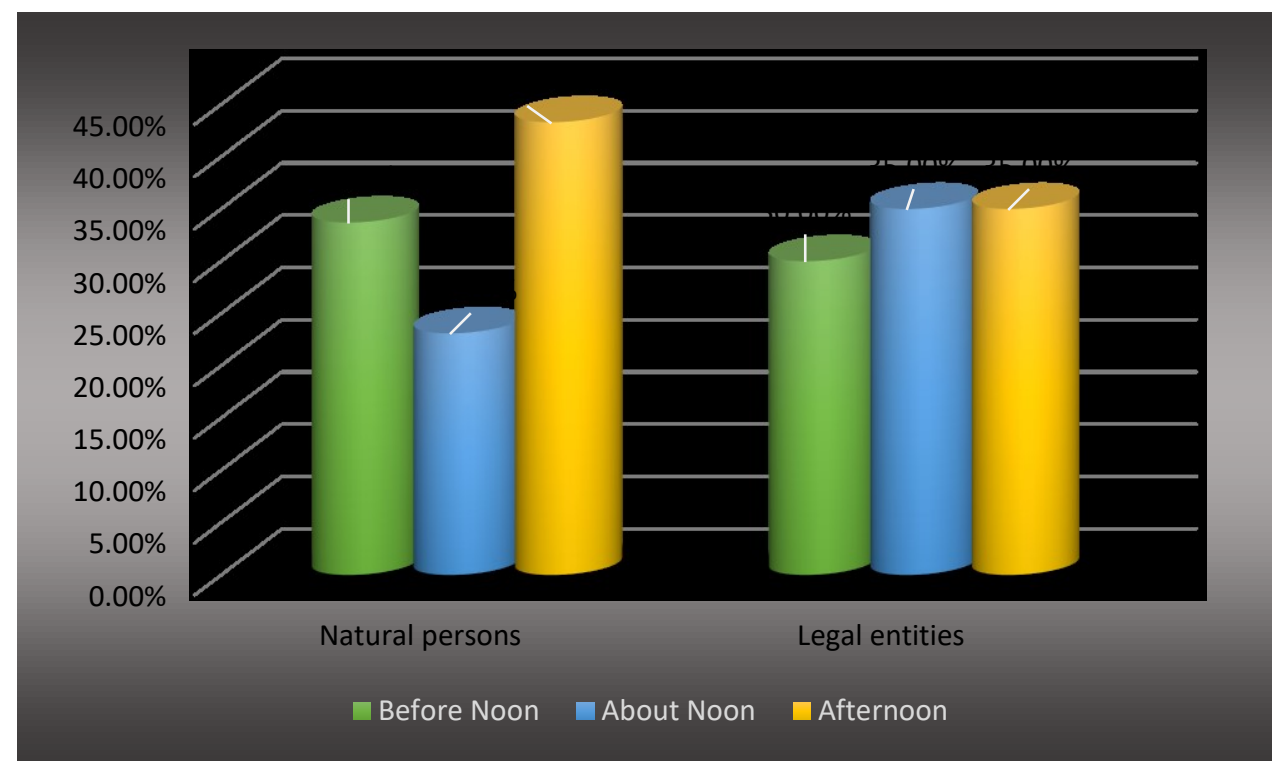

Fig. 4 Representation of the period of use of the service during the day by natural and legal persons

In analyzing the frequency of sending and receiving express shipments, the Mann-Whitney $U$ test was applied. The results indicate that there is a statistically significant difference between natural and legal persons in relation to the number of shipments that are sent during the year $(Z=-9.307 ; p<0.001)$, ie. received $(\mathrm{Z}=-8.636 ; \mathrm{p}<0.001)$. Fig. 4 shows the representation of the period of use of the service during the day by natural and legal persons. In this case, the Chi-square test was used and it was shown that there is no statistically significant correlation between the type of user and the parts of the day in which they use the service $(\chi 2=2.157 ; r=0.340)$. It is easy to notice that the use of the service by legal entities is approximately uniformly represented during the day. Individuals use the service more in the morning and in the afternoon, which is a result of time availability, which primarily depends on their working hours and obligations (Dobrodolac and Lazarević, 2019; Lazarević et al., 2020b). 
Within the research, attitudes about the importance of certain parameters of service (price, choice of services, safety, speed, time availability and territorial and financial accessibility) were examined. Fig. 5 shows the mean values of the estimates of these parameters by groups of respondents. The importance is defined by a five-level scale, where the value of 1 is irrelevant and 5 is very important.

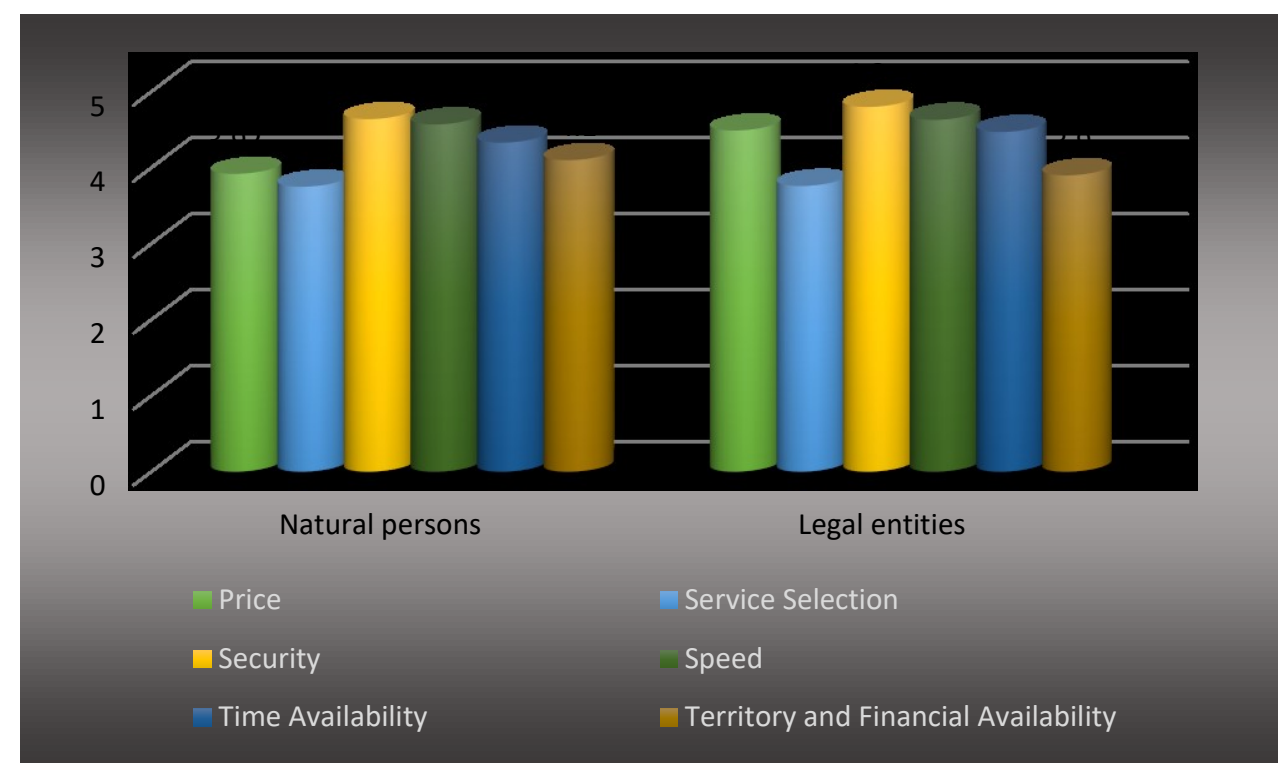

Fig. 5 Mean values of the assessment of the importance of parameters to natural persons and legal entities

In the part of the research that refers to the proposed NDS with improved time availability, the needs of the respondents for it in the previous year were first analyzed. The results are shown in Fig. 6.

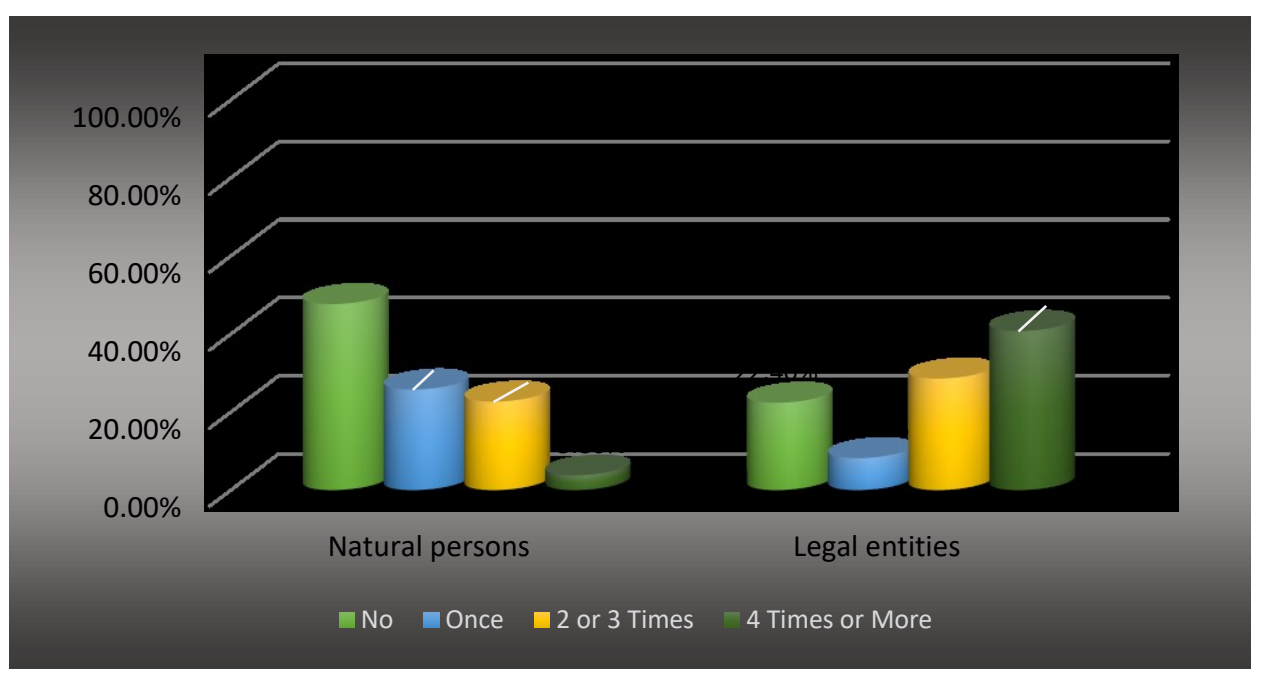

Fig. 6 Natural persons' and legal entities' need for the NDS in the previous year

Based on the obtained results, it can be concluded that most (40.8\%) legal entities needed the service 4 or more times. This indicator can be explained by their need to provide service in the period outside their own working hours (afternoon, evening, weekends ...) which would reduce the negative impact on the efficiency of their daily business activities. $22.4 \%$ of legal entities did not need the service in the same observed period of time, while for natural persons, this indicator is slightly less than half (47.7\%). The Chi - square test was applied, results $(\chi 2=46.829 ; \mathrm{r}<0.001)$ indicate that there is a statistically significant correlation between the need for service and the types of respondents (Dobrodolac and Lazarević, 2019; Lazarević et al., 2020b). 
After the needs, the respondents' interest in the NDS was researched. The results are shown in Fig. 7 and show that there is a strong interest of both individuals and legal entities.

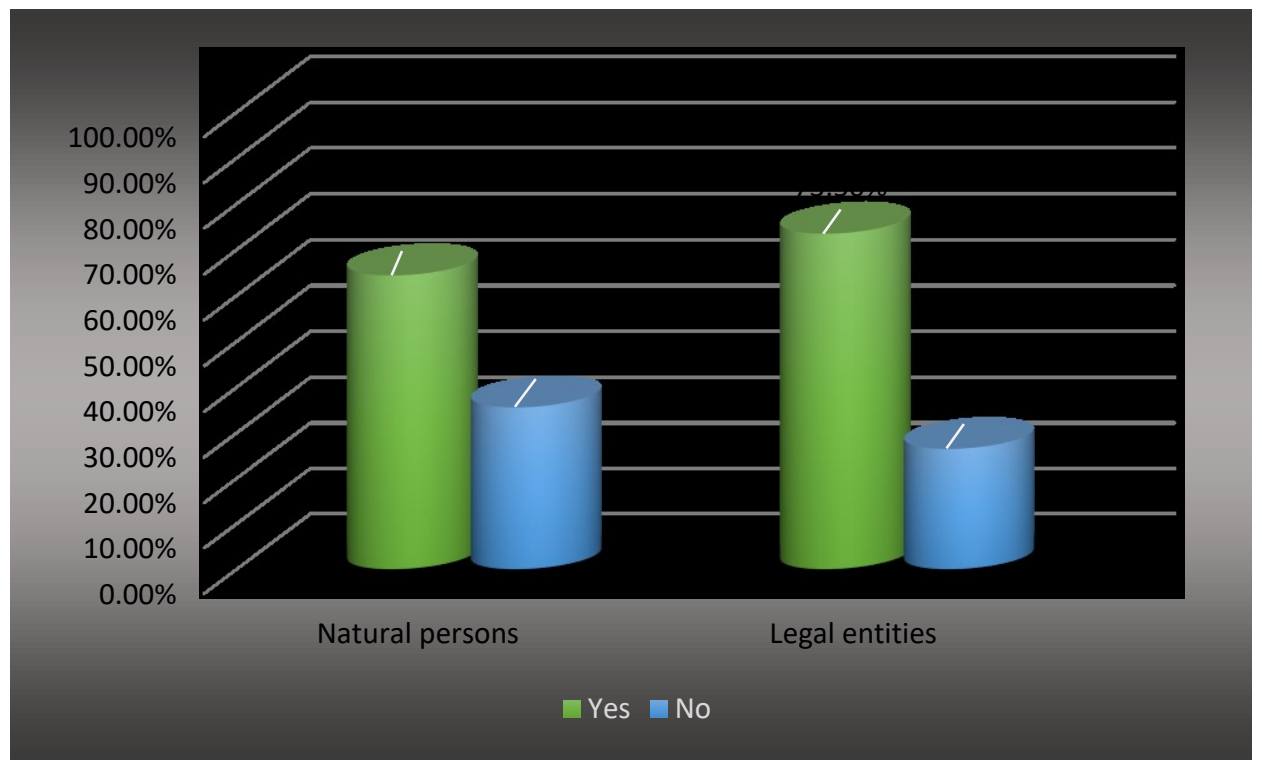

Fig. 7 Interest of natural persons and legal entities for the NDS

An analysis of the interest of EDS and those respondents who are not EDS users in the proposed NDS was performed. The results are shown in Fig. 8.

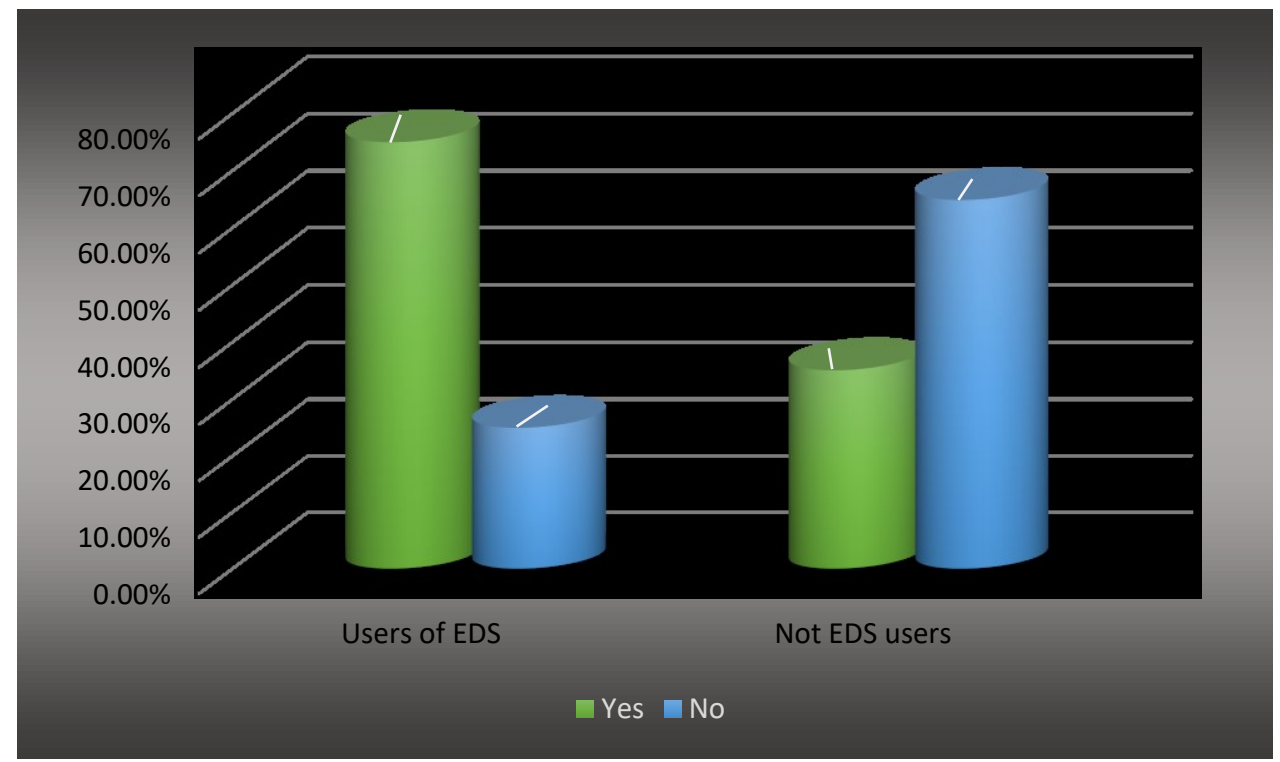

Fig. 8 Interests of respondents (EDS users/not EDS users) for NDS

The results indicate a significant interest of users of EDS (75\%), for the proposed, NDS. It is noticeable that the respondents who are not users EDS, showed less, but also significant interest in the new service (35.1\%). The results of the Chi-square test $(\chi 2=19.349 ; \mathrm{r}<0.001)$, confirm a statistically significant correlation between the type of respondents and interest in the service. The relationship between the frequency of need and interest in the new service was analyzed. The results of the analysis, ie the Chi square of the test $(\chi 2=57.060 ; r<0.001)$, show that there is a statistically significant correlation between them. Namely, a large part of the respondents who needed a service expressed interest in it. Respondents who did not need the service were not even interested in it (Dobrodolac and Lazarević, 2019; Lazarević et al., 2020b). 
The financial aspect was also analyzed. Respondents who needed the service also expressed a greater willingness to pay a higher price for the service. Respondents from both groups (who needed the service/who did not have the need), believe that a lower price of the service would motivate potential users to use it.

\section{CONCLUSIONS}

Different circumstances at the global and local levels, caused by modern business and the life style of an individual, have resulted in the appearance of changes in society. Namely, the habits and needs of people are changing with great speed and strong intensity, which has a great impact on the service sector. Postal companies, as one of the representatives in this area, found themselves under the impact of this change.

One of the serious challenges that has arisen for these companies is the time limit for users (individuals and legal entities) to use the express delivery service. As one of the possible solutions, a new express delivery service (NDS) with improved time availability has been proposed, which together with the existing delivery services (EDS) includes $24 / 7$ customer service. The concept is based on the maximum time coverage of the service during the week (together with existing services), which means that the service on weekdays is performed in the period from $7 \mathrm{pm}$ to $8 \mathrm{am}$, or on weekends from $3 \mathrm{pm}$ on Saturdays to 8 am on Mondays.

On the territory of the city of Belgrade, a survey was conducted on the attitudes and potential demands for the existing delivery services (EDS), as well as for the proposed new delivery service (NDS). The results of the research indicate that a significant number of respondents would need the proposed, new service and almost all respondents from this group expressed great interest in it. What is interesting to note is that the respondents who are not users of EDS services, showed significant interest in the new service, but respondents who needed the service also expressed a greater willingness to pay a higher price for the service. Additionally, respondents believe that a lower price of the service would motivate potential users to use it. In accordance with the results of the research and the derived indicators, it can be concluded that there is a pronounced need and interest in the market for the express delivery service with improved time availability.

\section{References}

Bergman, B. and Klefsjö, B. 2010. Quality from customer needs to customer satisfaction. Lund, Sweden: Studentlitteratur AB.

Brysland, A. and Curry, A. 2001. Service improvements in public services using SERVQUAL. Managing Service Quality: An International Journal, 11(6), pp. 389-401. https://doi.org/10.1108/09604520110410601

Dias, P.A., Yoshizaki, H., Favero, P. and Vieira, J.G.V. 2019. Daytime or overnight deliveries? Perceptions of drivers and retailers in São Paulo City. Sustainability, 11(22), 6316. https://doi.org/10.3390/su11226316

Dobrodolac, M., Lazarević, D., Švadlenka, L. and Živanović, M. 2016. A study on the competitive strategy of the universal postal service provider. Technology Analysis \& Strategic Management, 28(8), pp. 935-949. https://doi.org/10.1080/09537325.2016.1180357

Dobrodolac, M. and Lazarević, D. 2019. Analiza stavova i potreba za uslugom prenosa ekspres pošiljaka sa unapređenom vremenskom dostupnošću [Analysis of attitudes and needs for express delivery service with improved time availability]. In Proceedings of XXXVII PosTel 2019, Belgrade, Serbia, pp. 83-92. http://postel.sf.bg.ac.rs/simpozijumi/POSTEL2019/RADOVI\%20PDF/Postanski\%20saobracaj,\%20mrez e\%20i\%20servisi/3-Dobrodolac-Lazarevic.pdf 
Dobrodolac, M., Marković, G., Čubranić-Dobrodolac, M., and Čičević, S. 2012. A Model for the Allocation of Limited Resources for Technological Improvement: A Case of Courier Service, Engineering Economics, 23(4), pp. 348-356. https://doi.org/10.5755/j01.ee.23.4.1502

Dobrodolac, M., Marković, D., Čubranić-Dobrodolac, M., and Denda, N. 2014. Using work stress measurement to develop and implement a TQM programme: a case of counter clerks in Serbian Post, Total Quality Management and Business Excellence, 25(11-12), pp. 1262-1279. https://doi.org/10.1080/14783363.2012.704280

Edvardsson, B. 1998. Service quality improvement. Managing Service Quality: an International Journal, 8(2), pp. 142-149. https://doi.org/10.1108/09604529810206972

Görener, A. 2012. Comparing AHP and ANP: an application of strategic decisions making in a manufacturing company. International Journal of Business and Social Science, 3(11), pp. 194-208. http://ijbssnet.com/journals/Vol 3 No 11 June 2012/22.pdf

Kashiki, K., Fukuhara, T., Yamaguchi, A. and Suzuki, T. 2010. Analytical study on performance improvement of service availability in heterogeneous radio networks. IEICE Transactions on Communications, 93(12), pp. 3302-3310. https://doi.org/10.1587/transcom.E93.B.3302

Lazarević, D., Dobrodolac, M., Švadlenka, L. and Stanivuković, B. 2020a. A model for business performance improvement: a case of the postal company. Journal of Business Economics and Management, 21(2), pp. 564-592. https://doi.org/10.3846/ibem.2020.12193

Lazarević, D., Švadlenka, L., Radojičić, V. and Dobrodolac, M. 2020b. New Express Delivery Service and Its Impact on CO2 Emissions. Sustainability, 12(2), 456. https://doi.org/10.3390/su12020456

Pallant, J. 2011. SPSS Survival Manual: A step-by-step guide to data analysis using SPSS. Allen \& Unwin: Crows Nest.

Saaty, T.L. 1977. A scaling method for priorities in hierarchical structures. Journal of Mathematical Psychology, 15(3), pp.234-281. https://doi.org/10.1016/0022-2496(77)90033-5

Spajić, D. and Šapina, K. 2007. AMQM system for measuring the quality of postal services. PrometTraffic\&Transportation, 19(2), pp. 129-137. https://traffic.fpz.hr/index.php/PROMTT/article/view/944

Wang, X.P., Zhang, J. and Yang, T. 2014. Hybrid SWOT approach for strategic planning and formulation in China Worldwide Express Mail Service. Journal of Applied Research and Technology, 12(2), pp. 230-238. https://doi.org/10.1016/S1665-6423(14)72339-9 